AUTOR:

Fernando Maia Peixoto Filho

ORIENTADOR:

Prof. Dr. EDSON MARCHIORI

Prof. Dr. Renato Augusto

MOREIRA DE SÁ
Avaliação da bexiga fetal por meio da ultra-sonografia tridimensional - reprodutibilidade da técnica rotacional

Three-dimensional ultrasound fetal urinary bladder evaluation - reliability of rotational technique
Resumo de tese

Palavras-chave

Reprodutibilidade de testes Ultra-sonografia

Bexiga urinária Tamanho dos órgãos

Keywords

Test reproducibility Ultrasonography

Urinary bladder

Organ size

AUTORA:

Rita de CÁsSia Ferrer da Rosa MOtOOKa

ORIENTADORA:

Profa. Dra. Ceres Alves de Araújo

Resumo de tese

Palavras-chave

Infertilidade, Método de Rorschach, Aspectos emocionais

Keywords:

Infertility, Rorschach method Emotional aspects
Dissertação apresentada à Faculdade de Medicina da Universidade Federal Fluminense (UFF) para obtenção do Grau de Mestre em Medicina (Área de Concentração: Ciências Médicas), em 12 de junho de 2008.

OBJETIVO: investigar a reprodutibilidade intra e interobservador da aferição da bexiga fetal (BF) utilizando a ultra-sonografia (US) tridimensional (3D) Virtual Organ Computed-aided Analysis $\left(V O C A L^{\circledR}\right)$ comparando os ângulos de rotação de 15 e $30^{\circ}$. MÉTODOS: foram analisadas 240 aferições de volume da BF realizadas em 30 gestantes de baixo risco, com idade gestacional variando entre 22 e 39 semanas de gestação, por dois observadores independentes, cegos entre si. Todos os fetos foram examinados e nenhuma malformação detectável ao US foi observada. O volume de cada BF foi aferido duas vezes por cada observador, utilizando a técnica 3D VOCAL ${ }^{\circledR}$. Aferições de volume distintas com o uso de 12 e 6 planos foram obtidas depois de rotações seqüências de 15 e $30^{\circ}$, respectivamente. $O$ contorno interno da BF foi determinado manualmente, de forma cuidadosa, para excluir do cálculo de volume as estruturas adjacentes. O teste do sinal ranqueado de Wilcoxon foi utilizado para a comparação de amostra pareada nos casos de replicação intra e interobservador. A correlação ranqueada de Spearman foi utilizada para estudar a correlação entre os ângulos de $15^{\circ}$ e $30^{\circ}$. $\bigcirc$ método de Bland-Altman foi usado para investigar a concordância entre os observadores. RESULTADOS: a técnica 3D VOCAL ${ }^{\circledR}$ foi altamente reprodutível em nossa amostra. Não foi observada diferença significativa entre as medidas da BF pela técnica 3D VOCAL ${ }^{\circledR}$, variando por ângulo de rotação ou por observador. CONCLUSÕES: boas correlações foram observadas para os dois observadores, utilizando os ângulos de 15 e 30 $0^{\circ}$. Considerando que uma avaliação significativamente mais rápida pode ser obtida utilizando o ângulo de $30^{\circ}$, essa deve ser preferida na avaliação de volume da BF.

\section{Aspectos emocionais investigados na infertilidade método de Rorschach}

\section{Emotional aspects of infertility investigated with Rorschach method}

Dissertação apresentada ao Programa de Pós-graduação em Psicologia Clínica, Núcleo de Psicossomática e Psicologia Hospitalar da Pontifícia Universidade Católica de São Paulo (PUC-SP), para obtenção do Grau de Mestre, em 5 de setembro de 2008 .

INTRODUÇÃO: a infertilidade acomete de 10 a 15\% de casais em idade reprodutiva em todo o mundo: sua vivência é relatada como uma experiência dolorosa, abarcando a vida humana em toda sua complexidade e, portanto, deve ser compreendida além de seus aspectos biológicos. OBJETIVO: investigar o psiquismo de mulheres inférteis submetidas a trałamento de reprodução assistida por meio do método de Rorschach (Sistema Compreensivo). MÉTODOS: participaram deste estudo clínico descritivo 15 mulheres, com idade entre 27 e 38 anos, com diagnóstico de infertilidade no mínimo há dois anos e, no máximo, há cinco anos. Inscritas no programa de Reprodução Assistida do Centro de Referência da Saúde da Mulher (CRSM) do Hospital Pérola Byington. $\bigcirc$ critério de exclusão vetava participantes sob medicação psiquiátrica e também aquelas que após algum procedimento estivessem aguardando o resultado de uma possível gravidez. protocolo de pesquisa foi elaborado de forma que pudesse coletar dados da vivência emocional e enfrentamento da infertilidade. Instrumentos: ficha de identificação, entrevista-semidirigida, questionário Abipeme (socioeconômico) e método de Rorschach. Os conteúdos disfóricos e depressivos e a manifestação de estresse foram investigados pelo método de Rorschach. RESULTADOS: o método de Rorschach apontou que quatro participantes apresentaram constelação positiva para o índice de depressão (DEPI) e cinco apresentaram constelação positiva ao índice de déficit relacional (CDI). Entretanto, mesmo as participantes que não apresentaram constelação positiva para depressão, sugerem uma tonalidade disfórica e níveis de estresse expressivos em seu psiquismo. CONCLUSÕES: a análise dos resultados encontrados pelo método de Rorschach corroborou estudos anteriores que apontam a manifestação de estresse e depressão em mulheres submetidas a procedimentos de reprodução assistida. A categorização dos dados da entrevista semidirigida evidenciou aspectos mobilizadores no psiquismo destas mulheres. Todas as participantes da amostra relataram tristeza, frustração, impotência, angústia, ansiedade e sensação de "vazio". A tonalidade emocional expressa evidência o impacto desta vivência. 